\title{
Autotuning Method for a Fractional Order Controller for a Multivariable 13C Isotope Separation Column
}

\author{
Cristina I. Muresan, Robin De Keyser and Clara M. Ionescu
}

\begin{abstract}
The preferred controller design technique in industrial applications is based on autotuning procedures that do not involve knowledge about an actual mathematical model of the process. In this paper, a novel autotuning method for designing fractional order controllers is addressed. The proposed technique is simple and efficient. Previous research with respect to autotuning methods for fractional order controllers has considered exclusively the case of a single-inputsingle-output process. However, in this paper, a multivariable case study is preferred. The simulation results demonstrate the validity of the design technique.
\end{abstract}

Keywords: fractional order controllers, autotuning methods, multivariable processes

\section{INTRODUCTION}

In large industrial plants, the modeling of the processes may be a tedious task. Even if a mathematical model is obtained, the accuracy of the model is usually limited, leading to a necessity of designing robust controllers to account for modeling uncertainties or errors. It is quite usual in such cases, especially in industrial fields, to design simple PID controllers using auto-tuning methods that do not require an actual mathematical process model. One of these autotuning methods is the one developed by Ziegler and Nichols [1]. This was the first auto-tuning method, being based on simple measurements of the process critical gain and critical frequency. Its disadvantages have been long discussed with several other auto-tuning methods being proposed, such as those developed by Åström-Hägglund [2], [3], Tan, Lee and Wang [4], Hang, Åström and Ho [5], Chen and Moore [6], to name just a few.

Apart from these classical autotuning methods, the emergence of fractional calculus and its growing impact upon the design of controllers has led to the development of some autotuning methods for fractional order PIDs (FO-PID). These FO-PID controllers are in fact generalizations of the classical PID [7] and imply the use of a fractional integrator of order $\mu$ and a fractional differentiator of order $\lambda$. Although research in this domain has been scarce, some notable results in the field of fractional order autotuners may be mentioned such as the phase shaper [8], the relay test, based on an approach that considers an extension of the classical method used in the auto-tuning of integer order PID controllers [9]

Cristina I. Muresan is with Technical University of Cluj-Napoca, Department of Automation, Gh. Baritiu, no.26-28, Cluj-Napoca, Romania (e-mail: Cristina.Muresan@aut.utcluj.ro)

Robin De Keyser, Clara M. Ionescu are with Ghent University, Department of Electrical energy, Systems and Automation, Technologiepark, 913, 9052 Gent, Belgium ( e-mail: Robain.DeKeyser@UGent.be, ClaraMihaela.Ionescu@Ugent.be) or an autotuning procedure inspired from both the classical Ziegler-Nichols and Åström-Hägglund tuning methods [10]. These two last approaches are lengthy. The latter [10], requires first the use of the Ziegler-Nichols tuning procedure to determine the proportional and integrative gains of the controller, while the initial value of derivative gain is obtained using Åström-Hägglund method. Two nonlinear equations are derived in order to meet the phase margin specification. These are determined based on the critical frequency and critical gain obtained according to the Åström-Hägglund method. The method further assumes a fine tuning of the derivative gain in order to achieve the best numerical solution of these two equations. Optimization techniques applied to these two nonlinear equations are also required to determine the controller fractional orders, $\mu$ and $\lambda$. An optimization model is used to obtain a better step response of the closed loop system, in which the previously computed controller parameters are used as initial values for determining the new optimal values for the controller parameters. In [9], a separate fractional order PI controller (FO-PI) and a fractional order PD (FO-PD) controller with a filter are determined. The autotuning procedure is based on three performance specifications such as: a gain crossover frequency, a phase margin, along with the iso-damping property. The procedure is based on maximizing the robustness to plant gain variations.

In this paper, a novel autotuning method for fractional order PI controllers is proposed with a design based on meeting the three performance specifications: a gain crossover frequency, a phase margin and the iso-damping property. Such design procedure is based on the well-known tuning method of fractional order controllers [11], [12] that considers a mathematical model of the process to determine the magnitude, phase and phase slope of the process at the imposed gain crossover frequency. In this paper, the process model is unavailable, but instead a technique to determine the process magnitude, phase and phase slope is proposed.

Previous researches on autotuning methods for fractional order controllers have only considered single input single output process. In this paper, the proposed autotuning method is applied for a multivariable process.

The paper is structured as follows. In section 2, the proposed autotuning technique for a multivariable fractional order PI controller is addressed. Section 3 presents the simulation results considering the proposed case study, a 13 Carbon (13C) isotope separation column, while Section 4 contains the concluding remarks. 


\section{Proposed Auto-TUning Method FOR Multivariable PROCESSES}

The transfer function matrix of a multivariable process with $n$ inputs and $n$ outputs is given as:

$$
\mathrm{G}_{\mathrm{p}}(\mathrm{s})=\left[\begin{array}{ccc}
\mathrm{g}_{11}(\mathrm{~s}) & \ldots & \mathrm{g}_{1 \mathrm{n}}(\mathrm{s}) \\
\vdots & : & \vdots \\
\mathrm{g}_{\mathrm{n} 1}(\mathrm{~s}) & \ldots & \mathrm{g}_{\mathrm{nn}}(\mathrm{s})
\end{array}\right]
$$

The proposed autotuning method for the process described in (1), assumes a decentralized approach, with the inputoutput pairing selected based on the Relative Gain Array [13], obtained using steady state knowledge of the process. Once the input-output pairs are selected, $n$ individual FO-PI controllers are designed, having the transfer function as indicated below:

$$
\mathrm{H}_{\mathrm{FO}-\mathrm{PI}}(\mathrm{s})=\mathrm{k}_{\mathrm{p}}\left(1+\frac{\mathrm{k}_{\mathrm{i}}}{\mathrm{s}^{\mu}}\right)
$$

where $\mu \in(0 \div 2)$ is the fractional order and $\mathrm{k}_{\mathrm{p}}$ and $\mathrm{k}_{\mathrm{i}}$ are the proportional and integrative gains, respectively. A higher value of the fractional order $\mu$ could lead to an unstable closed loop system and should be avoided. The corresponding modulus and phase of the FO-PI controller in (2) may be easily computed as:

$$
\begin{aligned}
& \left|\mathrm{H}_{\mathrm{FO}-\mathrm{PI}}(\mathrm{j} \omega)\right|=\mathrm{k}_{\mathrm{p}} \sqrt{1+2 \mathrm{k}_{\mathrm{i}} \omega^{-\mu} \cos \frac{\pi \mu}{2}+\mathrm{k}_{\mathrm{i}}{ }^{2} \omega^{-2 \mu}} \\
& \angle \mathrm{H}_{\mathrm{FO}-\mathrm{PI}}(\mathrm{j} \omega)=-\mathrm{a} \tan \left(\frac{\mathrm{k}_{\mathrm{i}} \omega^{-\mu} \sin \frac{\pi \mu}{2}}{1+\mathrm{k}_{\mathrm{i}} \omega^{-\mu} \cos \frac{\pi \mu}{2}}\right)
\end{aligned}
$$

The autotuning of the FO-PI controllers is based on three performance specifications [11]: a gain crossover frequency $\omega_{\mathrm{gc}}$, a phase margin $\gamma_{\mathrm{k}}$ and the iso-damping property.

1. In order for the system to ensure the imposed gain crossover frequency, the following condition must hold:

$$
\left|\mathrm{H}_{\mathrm{FO}-\mathrm{PI}}\left(\mathrm{j} \omega_{\mathrm{gc}}\right)\right| \mathrm{M}_{\mathrm{m}}=1
$$

where $\mathrm{M}_{\mathrm{m}}$ is the modulus of the $m^{\text {th }}$ diagonal element in $\mathrm{G}_{\mathrm{p}}(\mathrm{s})$ and $\omega_{\mathrm{gc}_{\mathrm{m}}}$ is the gain crossover frequency for the $m^{\text {th }}$ input-output pair, with $m=1,2, \ldots, n$.

2. In order for a system to ensure a certain phase margin, the following condition must hold:

$$
\angle \mathrm{H}_{\mathrm{FO}-\mathrm{PI}}\left(\mathrm{j} \omega_{\mathrm{gc}_{\mathrm{m}}}\right)+\varphi_{\mathrm{m}}=-\pi+\gamma_{\mathrm{k}_{\mathrm{m}}}
$$

with $\varphi_{\mathrm{m}}$ the phase of the $m^{\text {th }}$ diagonal element and $\gamma_{\mathrm{k}_{\mathrm{m}}}$ the corresponding phase margin for the $m^{\text {th }}$ input-output pair.
3. In order for a system to ensure the iso-damping property, the following condition must hold:

$$
\left.\frac{\mathrm{d}\left(\angle \mathrm{H}_{\mathrm{FO}-\mathrm{PI}}(\mathrm{j} \omega)\right)}{\mathrm{d} \omega}\right|_{\omega=\omega_{\mathrm{gc}}}+\left.\frac{\mathrm{d}\left(\varphi_{\mathrm{m}}\right)}{\mathrm{d} \omega}\right|_{\omega=\omega_{\mathrm{gc} m}}=0
$$

As shown in the nonlinear equations (5)-(7), to completely tune the FO-PI/FO-PD controllers, the modulus, phase and phase slope of the process at the gain crossover frequency have to be known. The phase and magnitude of any stable process at a specific gain crossover frequency $\omega_{\mathrm{gc}_{\mathrm{m}}}$ may be easily determined by applying a sinusoidal input signal of frequency $\omega_{\mathrm{gc}_{\mathrm{m}}}$ to the process. To determine the phase slope of the process, a filtering technique is proposed as indicated in Fig. 1.

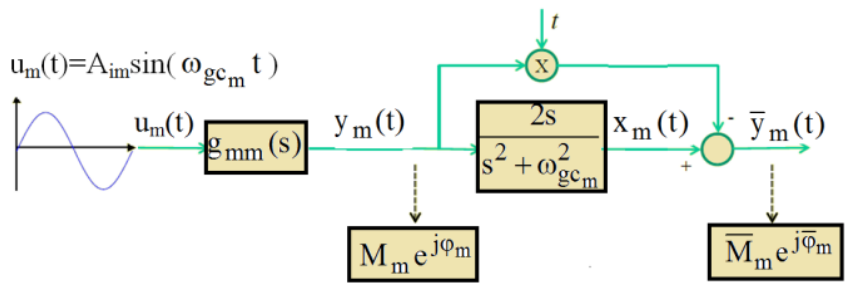

Fig. 1. Experimental scheme used to compute the phase slope of the process at the gain crossover frequency

The modulus and phase of each of the $n$ input-output pairs may be computed as:

$\mathrm{M}_{\mathrm{m}}=\frac{\mathrm{A}_{\mathrm{om}}}{\mathrm{A}_{\mathrm{im}}}$ and $\varphi_{\mathrm{m}}=\omega_{\mathrm{gc}_{\mathrm{m}}}\left(\mathrm{t}_{\mathrm{i}_{\mathrm{m}}}-\mathrm{t}_{\mathrm{o}_{\mathrm{m}}}\right)$

where $\mathrm{A}_{\text {om }}$ is the $m^{\text {th }}$ output amplitude $\mathrm{y}_{\mathrm{m}}(\mathrm{t}), \mathrm{A}_{\mathrm{im}}$ is the $m^{\text {th }}$ input amplitude $u_{m}(t)$ and $t_{i m}-t_{o m}$ is the time shift between the input $\mathrm{u}_{\mathrm{m}}(\mathrm{t})$ and output $\mathrm{y}_{\mathrm{m}}(\mathrm{t})$ signals, as indicated by $\tau$ in Figure 2.

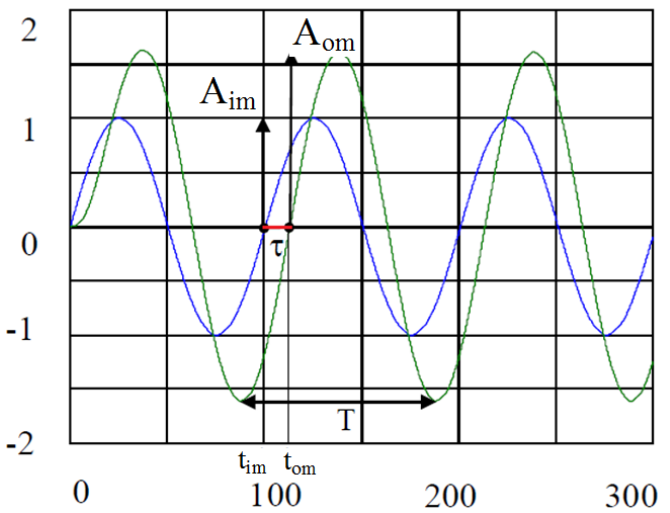

Fig. 2. Input $\mathrm{u}_{\mathrm{m}}$ (blue) and output $\mathrm{y}_{\mathrm{m}}$ (green) signals

According to Fig. 1, the following is obtained:

$\mathrm{U}_{\mathrm{m}}(\mathrm{s}) \cdot \mathrm{g}_{\mathrm{mm}}(\mathrm{s})=\mathrm{Y}_{\mathrm{m}}(\mathrm{s})$

$X_{m}(s)=\frac{2 s}{s^{2}+\omega_{g c_{m}}^{2}} \cdot Y_{m}(s)$ 
By replacing (9) into (10), the following relation is obtained:

$X_{m}(s)=\frac{2 s}{s^{2}+\omega_{\mathrm{gc}_{\mathrm{m}}}^{2}} \cdot U_{\mathrm{m}}(\mathrm{s}) \cdot \mathrm{g}_{\mathrm{mm}}(\mathrm{s})$

where $U_{m}(s)=\frac{A_{i m} \omega_{g c_{m}}}{s^{2}+\omega_{g c_{m}}^{2}}$ is the Laplace transform of the sinusoidal input signal $u_{m}(t)=A_{i m} \sin \left(\omega_{g c_{m}} t\right)$ given in Fig. 1, The derivative of this signal with respect to the Laplace variable $s$ is given as:

$\frac{\mathrm{dU}_{\mathrm{m}}(\mathrm{s})}{\mathrm{ds}}=-\frac{2 \mathrm{~A}_{\mathrm{im}} \omega_{\mathrm{gc}_{\mathrm{m}}} \mathrm{s}}{\left(\mathrm{s}^{2}+\omega_{\mathrm{gc} \mathrm{m}}^{2}\right)^{2}}$

Combining (11) and (12), the following equation is determined:

$X_{m}(s)=-\frac{d U_{m}(s)}{d s} \cdot g_{m m}(s)$

Considering again Fig. 1, the following is obtained:

$\bar{y}_{m}(t)=x_{m}(t)-t \cdot y_{m}(t)$

Signal $\bar{y}_{m}(t)$ is the output of the process derivative, as it will be shown next:

$$
\bar{Y}_{\mathrm{m}}(\mathrm{s})=\mathrm{U}_{\mathrm{m}}(\mathrm{s}) \cdot \frac{\mathrm{dg}_{\mathrm{mm}}(\mathrm{s})}{\mathrm{ds}}
$$

Consider first the derivative of the process output signal $\mathrm{Y}_{\mathrm{m}}(\mathrm{s}), \frac{\mathrm{dY}_{\mathrm{m}}(\mathrm{s})}{\mathrm{ds}}=\mathcal{L}\left(-\mathrm{t} \cdot \mathrm{y}_{\mathrm{m}}(\mathrm{t})\right)$, which leads to:

$-\mathrm{t} \cdot \mathrm{y}_{\mathrm{m}}(\mathrm{t})=\mathcal{L}^{-1}\left(\frac{\mathrm{dY} \mathrm{m}(\mathrm{s})}{\mathrm{ds}}\right)=\mathcal{L}^{-1}\left(\frac{\mathrm{d}\left[\mathrm{g}_{\mathrm{mm}}(\mathrm{s}) \cdot \mathrm{U}_{\mathrm{m}}(\mathrm{s})\right]}{\mathrm{ds}}\right)$

Then,

$-\mathrm{t} \cdot \mathrm{y}_{\mathrm{m}}(\mathrm{t})=\mathcal{L}^{-1}\left(\frac{\mathrm{dg}_{\mathrm{mm}}(\mathrm{s})}{\mathrm{ds}} \cdot \mathrm{U}_{\mathrm{m}}(\mathrm{s})\right)+\mathcal{L}^{-1}\left(\frac{\mathrm{d} \mathrm{U}_{\mathrm{m}}(\mathrm{s})}{\mathrm{ds}} \cdot \mathrm{g}_{\mathrm{mm}}(\mathrm{s})\right)$

Replacing (15) and (13) into (17) leads to:

$-\mathrm{t} \cdot \mathrm{y}_{\mathrm{m}}(\mathrm{t})=\mathcal{L}^{-1}\left(\overline{\mathrm{Y}}_{\mathrm{m}}(\mathrm{s})\right)+\mathcal{L}^{-1}\left(-\mathrm{X}_{\mathrm{m}}(\mathrm{s})\right)$

From this last relation in (18), it is obvious that the $\bar{y}_{m}(t)$ signal is the output of the process transfer function derivative (with respect to $s$ ), considering a sinusoidal signal applied at its input. Then, the experimental scheme in Fig. 2 may be used to determine not only the modulus $\mathrm{M}_{\mathrm{m}}$ and phase $\varphi_{\mathrm{m}}$ of each input-output pair, but also the corresponding phase slope. According to Fig. 2, the following notations will be used for the modulus and phase of the derivative $\frac{\operatorname{dg}_{\mathrm{mm}}(\mathrm{s})}{\mathrm{ds}}$, denoted as $\overline{\mathrm{M}}_{\mathrm{m}}$ and $\bar{\varphi}_{\mathrm{m}}$. Since the performance specifications in (5)-(7) are given in the frequency domain, the derivative of $\frac{\operatorname{dg}_{\mathrm{mm}}(\mathrm{s})}{\mathrm{ds}}$ at the gain crossover frequency is computed as:

$\left.\frac{\operatorname{dg}_{m m}(j \omega)}{d(j \omega)}\right|_{\omega=\omega_{g c_{m}}}=\bar{M}_{m} e^{j \bar{\varphi}_{m}}$
or
$-\left.j \frac{\operatorname{dg}_{m m}(j \omega)}{d \omega}\right|_{\omega=\omega_{g c_{m}}}=\bar{M}_{m} e^{j \bar{\varphi}_{m}}$

where both $\overline{\mathrm{M}}_{\mathrm{m}}$ and $\bar{\varphi}_{\mathrm{m}}$ may be determined experimentally similarly to (8) as:

$\bar{M}_{\mathrm{m}}=\frac{\mathrm{A}_{\overline{\mathrm{y}}_{\mathrm{m}}}}{\mathrm{A}_{\mathrm{im}}}$ and $\bar{\varphi}_{\mathrm{m}}=\omega_{\mathrm{gc}_{\mathrm{m}}}\left(\mathrm{t}_{\mathrm{i}_{\mathrm{m}}}-\mathrm{t}_{\overline{\mathrm{y}}_{\mathrm{m}}}\right)$

with $\mathrm{A}_{\bar{y}_{\mathrm{m}}}$ - the amplitude of the sinusoidal signal $\overline{\mathrm{y}}_{\mathrm{m}}(\mathrm{t})$ and $\mathrm{t}_{\mathrm{i}_{\mathrm{m}}}-\mathrm{t}_{\overline{\mathrm{y}}_{\mathrm{m}}}$ - the time shift between the two signals $\mathrm{u}_{\mathrm{m}}(\mathrm{t})$ and $\bar{y}_{\mathrm{m}}(\mathrm{t})$.

Considering now that $g_{m m}(j \omega)=M_{m} e^{j \varphi_{m}}$ is replaced into (19), leads to:

$-\left.j \frac{d M_{m}}{d \omega}\right|_{\omega=\omega_{g c_{m}}}+\left.M_{m} \frac{d \varphi_{m}}{d \omega}\right|_{\omega=\omega_{g c_{m}}}=\bar{M}_{m} e^{j\left(\bar{\varphi}_{m}-\varphi_{m}\right)}$

Replacing into (21) the relation for the right hand side, $\overline{\mathrm{M}}_{\mathrm{m}} \mathrm{e}^{\mathrm{j}\left(\bar{\varphi}_{\mathrm{m}}-\varphi_{\mathrm{m}}\right)}=\overline{\mathrm{M}}_{\mathrm{m}} \cos \left(\bar{\varphi}_{\mathrm{m}}-\varphi_{\mathrm{m}}\right)+\mathrm{j} \overline{\mathrm{M}}_{\mathrm{m}} \sin \left(\bar{\varphi}_{\mathrm{m}}-\varphi_{\mathrm{m}}\right)$ and equating the real and imaginary parts of the left and right hand sides of (21), leads to the final relation for determining the phase slope at the specified gain crossover frequency $\omega_{\mathrm{gc}_{\mathrm{m}}}$ :

$\left.\frac{\mathrm{d} \varphi_{\mathrm{m}}}{\mathrm{d} \omega}\right|_{\omega=\omega_{\mathrm{gc} m}}=\frac{\overline{\mathrm{M}}_{\mathrm{m}}}{\mathrm{M}_{\mathrm{m}}} \cos \left(\bar{\varphi}_{\mathrm{m}}-\varphi_{\mathrm{m}}\right)$

Then, a simple sinusoidal experiment is performed on each input-output signal pairs, while the rest of the input signals are kept constant. Finally, the output signal is filtered as indicated in Fig. 2 to obtain the $\bar{y}_{\mathrm{m}}(\mathrm{t})$ signal, offline. Using (8) and (22) the modulus, phase and phase slope associated to each transfer function of the input-output pairs are determined. Once these are available, optimization techniques or graphical methods are used to solve the nonlinear equations in (5)-(7) and compute the FO-PI controllers parameters [11], [12]. To achieve this, firstly the 
integrative gain is computed as a function of the fractional order $\mu$, based on (6) and (7). Then, the two curves are plotted as a function of $\mu$, with their intersection point giving the final values for the integrative gain $\mathrm{k}_{\mathrm{i}}$ and the fractional order $\mu$. Once these two parameters are determined, the modulus condition in (5) is used to compute the proportional gain $\mathrm{k}_{\mathrm{p}}$.

\section{Simulation Results On A 13C IsOtope SEPARATION COLUMN}

To illustrate the autotuning method, a three input-three output $13 \mathrm{C}$ isotope separation column is used as a case study. The process is characterized by large time constants and large time delays. The process and equipment have been previously described in [14], [15], [16]. Simple experiments on the column have led to a steady state gain matrix and the associated RGA number:

$$
\begin{aligned}
\mathrm{G}_{\mathrm{p}}(\mathrm{s}=0) & =\left[\begin{array}{ccc}
-1.318 & 0.569 & 0 \\
-0.882 & 0.882 & -9.386 \\
-0.140 & 0.063 & 8.585
\end{array}\right] \\
\mathrm{RGA} & =\left(\begin{array}{ccc}
1.88 & -0.89 & 0 \\
-0.75 & 1.75 & 0.006 \\
-0.13 & 0.14 & 0.99
\end{array}\right)
\end{aligned}
$$

The RGA result in (24) suggests that a diagonal pairing $\mathrm{y}_{\mathrm{m}}$ $\mathrm{u}_{\mathrm{m}}$, with $m=1,2,3$, diminishes the interactions. Then, three FO-PI controllers will be designed using the autotuning method described in Section II.

The performance specifications for the first input-output loop refer to a gain crossover frequency $\omega_{\mathrm{gcl}}=0.018 \mathrm{rad} / \mathrm{s}$, a phase margin $\varphi_{\mathrm{m} 1}=70^{\circ}$ and the iso-damping property. The auto-tuning of a FO-PI controller, as described in Section 2, starts with an experimental test similar to Figure 1, where the sinusoidal input signal is applied with a frequency $\omega_{\mathrm{gcl}}=0.018 \mathrm{rad} / \mathrm{s}$ and $\mathrm{A}_{\mathrm{i} 1}=1$. The experimental results are given in Figure 3 , where the amplitude $A_{i 1}$ of the input signal is measured at $t_{i 1}=436.4 \mathrm{~s}$. Similarly, the amplitude of the output signal is $A_{o 1}=1.28$ at $t_{o 1}=459.2 \mathrm{~s}$. Using (8), the parameters $\mathrm{M}_{1}$ and $\varphi_{1}$ are computed, with $\mathrm{M}_{1}=1.28$ and $\varphi_{1}=-0.41 \mathrm{rad}$. The amplitude of $\bar{y}_{1}(\mathrm{t})$ is also determined from Fig. 3, $\mathrm{A}_{\bar{y}_{1}}=29.12$ at $\mathrm{t}_{\bar{y}_{1}}=639.5 \mathrm{~s}$. Then, using (20), $\overline{\mathrm{M}}_{1}=29.12$ and $\bar{\varphi}_{1}=-3.65 \mathrm{rad}$. Finally, using (22), the phase slope is computed as $\left.\frac{\mathrm{d} \varphi_{1}}{\mathrm{~d} \omega}\right|_{\omega=0.018}=-22.46 \mathrm{~s}$.

With the modulus, phase and phase slope determined experimentally, the system of equations in (5)-(7) is solved to determine the parameters: $\mathrm{k}_{\mathrm{p} 1}=0.27, \mathrm{k}_{\mathrm{i} 1}=0.0267$ and $\mu_{1}=1.176$. The transfer function of the designed FO-PI controller is:

$$
\mathrm{H}_{\mathrm{FO}-\mathrm{PI}_{1}}(\mathrm{~s})=0.27\left(1+\frac{0.0267}{\mathrm{~s}^{1.176}}\right)
$$

The performance specifications for the second input-output loop refer to a gain crossover frequency $\omega_{\mathrm{gc} 2}=0.03 \mathrm{rad} / \mathrm{s}$, a phase margin $\varphi_{\mathrm{m} 2}=67^{\circ}$ and the iso-damping property. For the auto-tuning of a FO-PI controller an experimental test similar to Figure 1 is performed, with the sinusoidal input signal having a frequency $\omega_{\mathrm{gc} 2}=0.03 \mathrm{rad} / \mathrm{s}$ and $\mathrm{A}_{\mathrm{i} 2}=1$. The experimental results are given in Figure 4, where the amplitude $A_{i 2}$ of the input signal is measured at $t_{i 2}=261.5 \mathrm{~s}$. Similarly, the amplitude of the output signal is $\mathrm{A}_{02}=0.66$ at $\mathrm{t}_{\mathrm{o} 2}=300.7 \mathrm{~s}$. Using (8), the parameters $\mathrm{M}_{2}$ and $\varphi_{2}$ are computed, with $\mathrm{M}_{2}=0.66$ and $\varphi_{2}=-1.176 \mathrm{rad}$. The amplitude of $\overline{\mathrm{y}}_{2}(\mathrm{t})$ is also determined from Figure 4, $\mathrm{A}_{\bar{y}_{2}}=23.72$ at $\mathrm{t}_{\overline{\mathrm{y}}_{2}}=420.12 \mathrm{~s}$. Then, using (20), $\overline{\mathrm{M}}_{2}=23.72$ and $\bar{\varphi}_{2}=-4.76 \mathrm{rad}$. Finally, using (22), the phase slope is computed as $\left.\frac{\mathrm{d} \varphi_{2}}{\mathrm{~d} \omega}\right|_{\omega=0.03}=-32.28 \mathrm{~s}$.

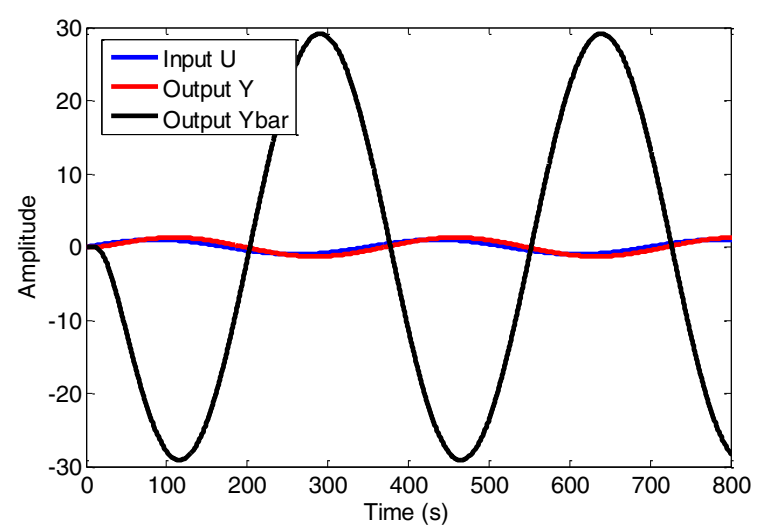

Fig. 3. Experimental results for the first input-output loop

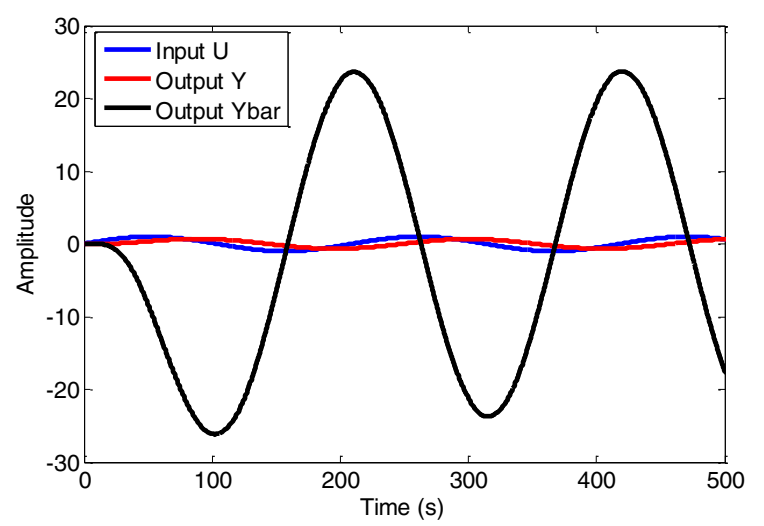

Fig. 4. Experimental results for the second input-output loop

With the modulus, phase and phase slope determined experimentally, the system of equations in (5)-(7) is solved to determine the parameters: $\mathrm{k}_{\mathrm{p} 2}=1.58, \mathrm{k}_{\mathrm{i} 2}=0.0082$ and $\mu_{2}=1.29$. The transfer function of the designed FO-PI controller is:

$$
\mathrm{H}_{\mathrm{FO}-\mathrm{PI}_{2}}(\mathrm{~s})=1.58\left(1+\frac{0.0082}{\mathrm{~s}^{1.29}}\right)
$$

Finally, for the third input-output loop, the performance specifications refer to a gain crossover frequency $\omega_{\mathrm{gc} 3}=1.8 \mathrm{rad} / \mathrm{s}$, a phase margin $\varphi_{\mathrm{m} 2}=66^{\circ}$ and the iso-damping property. For the auto-tuning of a FO-PI controller an experimental test similar to Figure 1 is performed, with the 
sinusoidal input signal having a frequency $\omega_{\mathrm{gc} 3}=1.8 \mathrm{rad} / \mathrm{s}$ and $A_{i 3}=1$. The experimental results are given in Figure 5, where the amplitude $\mathrm{A}_{\mathrm{i} 3}$ of the input signal is collected at $t_{\mathrm{i} 3}=$ 11.35s. The amplitude of the output signal is $\mathrm{A}_{03}=4.12$ at $\mathrm{t}_{\mathrm{o} 3}=11.945 \mathrm{~s}$. Using (8), the parameters $\mathrm{M}_{3}$ and $\varphi_{3}$ are computed, with $\mathrm{M}_{3}=4.12$ and $\varphi_{3}=-1.071 \mathrm{rad}$. The amplitude of $\bar{y}_{3}(t)$ is also determined from Figure 5, $\mathrm{A}_{\bar{y}_{3}}=2.01$ at $t_{\bar{y}_{3}}=14.3 \mathrm{~s}$. Then, using (20), $\overline{\mathrm{M}}_{3}=2.01$ and $\bar{\varphi}_{3}=-5.31 \mathrm{rad}$. Finally, using (22), the phase slope is computed as $\left.\frac{\mathrm{d} \varphi_{3}}{\mathrm{~d} \omega}\right|_{\omega=1.8}=-0.22 \mathrm{~s}$.

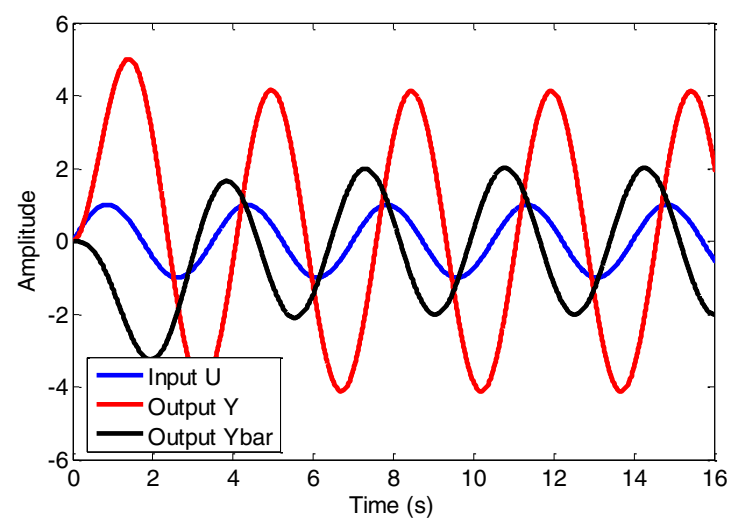

Fig. 5. Experimental results for the third input-output loop

With the modulus, phase and phase slope determined experimentally, the system of equations in (5)-(7) is solved to determine the parameters: $\mathrm{k}_{\mathrm{p} 3}=0.13, \mathrm{k}_{\mathrm{i} 3}=2.6$ and $\mu_{3}=0.942$. The transfer function of the designed FO-PI controller is:

$H_{F O-P I_{3}}(s)=0.13\left(1+\frac{2.6}{s^{0.942}}\right)$

The closed loop simulation results considering the process as modeled in [14], [16] are given in Figure 6, considering a step change in the reference of the first output signal $y_{1}$. The final multivariable controller is given as:

$$
\mathrm{G}_{\mathrm{C}}(\mathrm{s})=\left(\begin{array}{ccc}
\mathrm{H}_{\mathrm{FO}-\mathrm{PI}_{1}}(\mathrm{~s}) & 0 & 0 \\
0 & \mathrm{H}_{\mathrm{FO}-\mathrm{PI}_{2}}(\mathrm{~s}) & 0 \\
0 & 0 & \mathrm{H}_{\mathrm{FO}-\mathrm{PI}_{3}}(\mathrm{~s})
\end{array}\right)
$$

To implement the controllers, the Oustaloup Recursive Approximation method is used [17]. Fig. 6 a) shows the $y_{1}$ output, while Fig. 6 b) and Fig. 6 c) show the interaction responses of $y_{2}$ and $y_{3}$. The corresponding control signals are given in Fig. $6 \mathrm{~d}$ ), e) and f).

The simulation results in Figure 6 show that the multivariable fractional order controller designed using the proposed autotuning method is robust to modeling uncertainties, maintaining a low overshoot in the case of the nominal system, as well as in the case of $\pm 30 \%$ gain estimation errors. The control effort is acceptable, however, there is strong interaction present especially in the second output $y_{2}$.

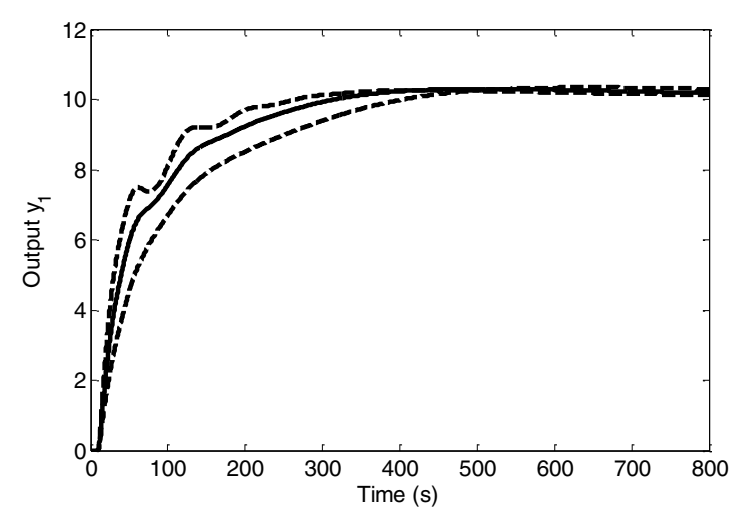

a)

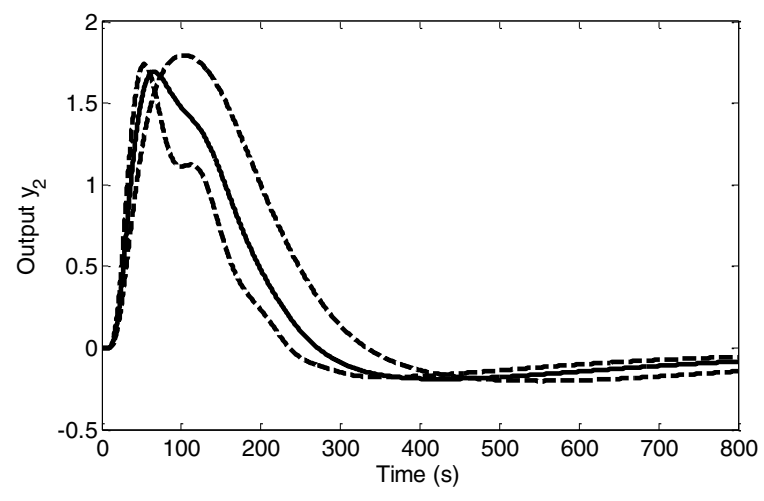

b)

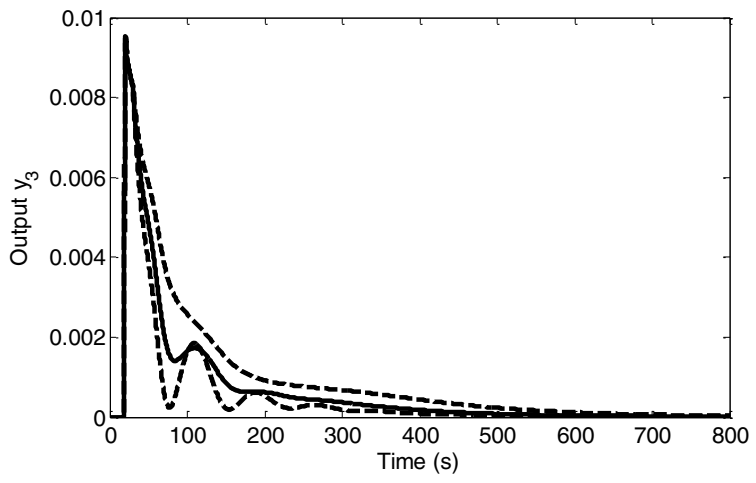

c)

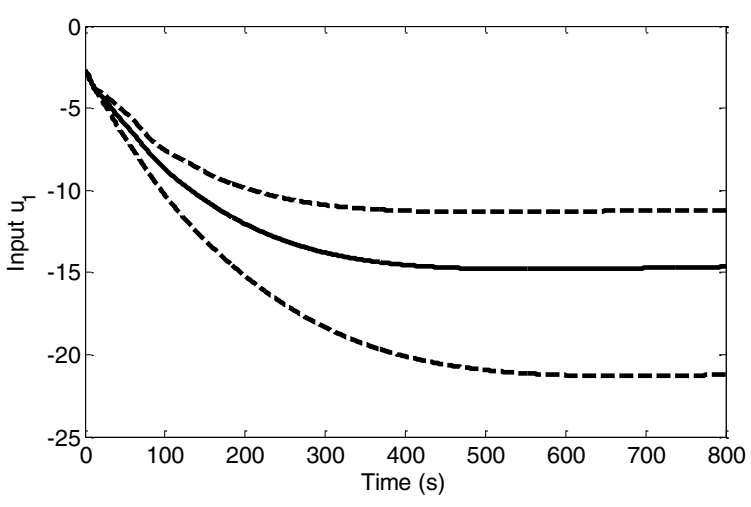

d) 


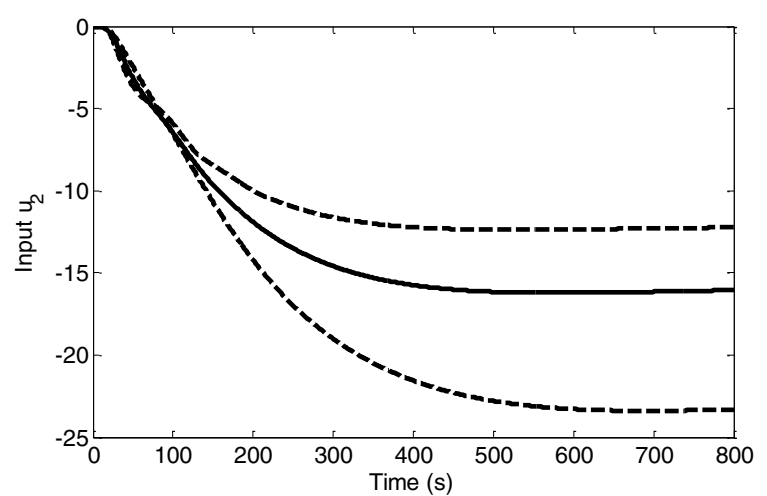

e)

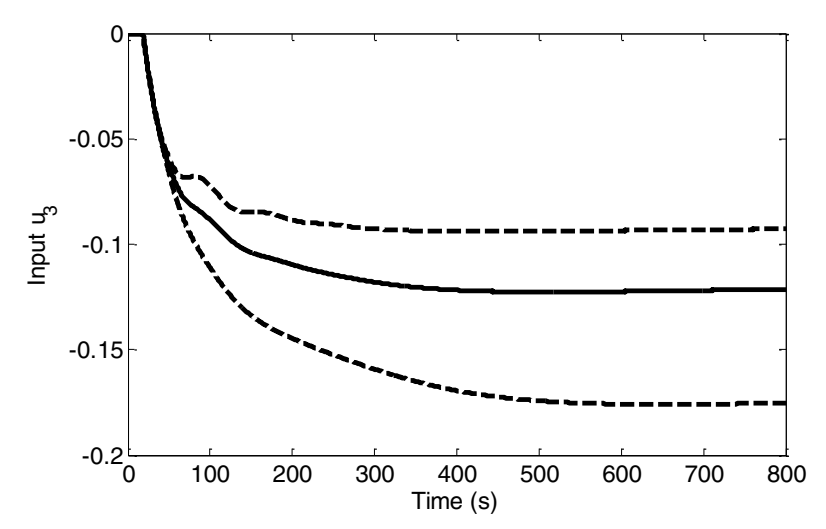

f)

Fig. 6. Output and input signals of the closed loop system (continuous line- nominal system, dashed line $- \pm 30 \%$ gain estimation errors)

\section{CONCLUSION}

In this paper, a novel autotuning technique for designing fractional order controllers has been proposed. The autotuning procedure is based on imposing a set of three performance criteria that refer to a certain gain crossover frequency, a certain phase margin, as well as the isodamping property. These performance specifications have been used considerably and most often in designing fractional order controllers, but in the presence of a mathematical model of the process. In this paper, similar results to the classical tuning techniques for fractional order controllers are obtained but in the absence of a process model. The efficiency and simplicity of the design is demonstrated numerically, through a case study that considers a multivariable system.

Although robust, the simulation results also show a considerable amount of interaction, because of the high couplings in the multivariable system. Further research includes the possibility of using the proposed autotuning method for designing fractional order controllers together with a steady state decoupling technique to improve the closed loop response and reduce interactions.

\section{ACKNOWLEDGMENT}

This work was partially supported by a grant of the Romanian National Authority for Scientific Research and Innovation, CNCS - UEFISCDI, project number PN-II-RUTE-2014-4-1465, contract number 38/2015.

\section{REFERENCES}

[1] Ziegler JG, Nichols NB. Optimum settings for automatic controllers. Trans ASME 1942; 64: 759-768

[2] Åström K.J, Hägglund T. Revisiting the Ziegler-Nichols step response method for PID control. J Process Contr 2004; 14: 635-650

[3] Åström K.J, Hägglund T. Automatic tuning of simple regulators with specifications on phase and amplitude margins. Automatica 1984; 20: 645-651

[4] Tan KK, Lee TH, Wang QG. Enhanced automatic tuning procedure for process control of PI/PID controllers. AlChE J 1996; 42: 25552562

[5] Hang CC, Åström K.J, Ho WK. Refinements of the Ziegler-Nichols tuning formula. IEE Proc D 1991; 138: 111-118

[6] Chen YQ, Moore KL. Relay feedback tuning of robust PID controllers with iso-damping property. Trans Syst Man Cybern 2005; 35: 23-31

[7] Podlubny, I. Fractional-order systems and PID-controllers. IEEE Trans Autom Control 1999; 44: 208-214

[8] Chen YQ, Moore KL, Vinagre BM, Podlubny I. Robust PID controller autotuning with a phase shaper. In: Proceedings of the First IFAC workshop on fractional differentiation and its applications, Bordeaux, France, 2004. p. 162-167.

[9] Monje CA,Vinagre BM, Feliu V, Chen YQ. Tuning and auto-tuning of fractional order controllers for industry applications. Control Eng Pract 2008; 16: 798-812.

[10] Yeroglu C, Onat C, Tan N. A new tuning method for PI $\lambda \mathrm{D} \mu$ controller. In: Proceedings of the International Conference on Electrical and Electronics Engineering ELECO 2009 II, Bursa, turkey, 2009. p. 312-316

[11] Monje CA, Chen YQ, Vinagre B, Xue D, Feliu V. Fractional order Systems and Controls: Fundamentals and Applications. Berlin: Springer Verlag; 2010.

[12] Muresan CI, Folea S, Mois G, Dulf EH. Development and Implementation of an FPGA Based Fractional Order Controller for a DC Motor. Mechatronics 2013; 23: 798-804.

[13] E.H. Bristol, "On a New Measure of Interaction for Multivariable Process Control", IEEE Transactions on Automatic Control, Vol. AC-11, pp. 131-134, January 1966

[14] C.I. Pop (Muresan), C.M. Ionescu, R. De Keyser, "Time delay compensation for the secondary processes in a multivariable carbon isotope separation unit", Chemical Engineering Science, vol. 80, pp. 205-218, 2012

[15] Muresan, C.I., Dulf, E.H., Both, R. (2015), Comparative analysis of different control strategies for a train of cryogenic 13C separation columns, Chemical Engineering and Technology, vol. 38, no. 4, pp. 619-631, DOI: 10.1002/ceat.201400550

[16] Muresan, C.I., Dulf, E.H., Both, R., Ionescu, C.M., Nascu, I. (2014), Improving performance for a $13 \mathrm{C}$ isotope separation plant using multivariable fractional order controllers, International Conference on Fractional Differentiation and its Applications, pp. 1-6, DOI: 10.1109/ICFDA.2014.6967385, 23-25 June, Catania, Italy

[17] A. Oustaloup, F. Levron, B. Mathieu, F.M. Nanot, Frequency-band complex noninteger differentiator: characterization and synthesis, IEEE Trans. Circuits Syst. I Fundam. Theory Appl., vol. 47, no. 1, pp. 25-39, 2000 